\title{
SOCIOCULTURAL DYNAMICS OF SUSTAINABLE DEVELOPMENT: FORMATION OF HUMAN POTENTIAL IN THE PROCESS OF INTEGRATED ECOLOGICAL AND ECONOMIC TRAINING
}

\author{
ARTEM SALAMATOV ${ }^{1}$, DARIA GORDEEVA $^{2} \&$ ALEXEY AGAPOV $^{3}$ \\ ${ }^{1}$ Department of Economic Theory and Regional Development, Chelyabinsk State University, Russian Federation \\ ${ }^{2}$ Department of Economics, Management and Law, South Ural State Humanitarian and Pedagogical University, \\ Russian Federation \\ ${ }^{3}$ Department of Chemistry, Ecology and Methods of Teaching Chemistry, South Ural State Humanitarian and \\ Pedagogical University, Russian Federation
}

\begin{abstract}
In modern society, the analysis of human potential includes the assessment or conditional accounting of its intellectual stock and future opportunities. The problem of preserving, developing and realizing human potential is the subject of increased public attention. It is necessary to choose a new development strategy, an innovative and promising path based on the development of new technologies, where the decisive role of the intellectual forces of society. The education system is a 'forge' of human potential, a kind of source of unlimited resources of intelligence, thanks to which it becomes possible to form fundamentally new ecocentric values in the developing world. Awareness of the unity and balance of socio-ecological-economic interests, which are the basis of the life of mankind, led to a fundamental idea about the transition of world-management thought to a new way of making safe environmental and economic strategic decisions and the rejection of the old, extensive path that has not justified itself. Maintaining balance in the ecological and economic systems of the intensively developing technosphere is unacceptable without a person's adequate understanding of the ongoing changes associated with his continuous production and economic activities. The formulated educational, ecological and economic paradigm creates at the same time a fundamental basis for the formation of the orientation of the student's personality, capable of realizing and self-realization of his capabilities in the field of ecology and economics, socially stable and easily adaptable, capable of developing and changing his own strategy in the transforming circumstances of life. In light of the goals and objectives of the integrated environmental and economic education, it is necessary to revise generally accepted ideas about the causes of the degradation of the planet's ecosystem and the slowdown in global economic growth, which are not so much technological progress as the person himself, his personal qualities and personality orientation, the formation of which depends on the field of education. The developed principles of integrated environmental and economic education are considered by us as an effective tool for the training of highly qualified specialists who possess the entire set of professional knowledge and value orientations that correspond to the realities of the current unstable environmental and economic state of social development. The content of ecological and economic education serves as a factor of integration of natural science and humanitarian paradigms, and the core of this integration is ecological and economic values, the orientation of which determines the appropriate human behavior.
\end{abstract}

Keywords: sustainable development, human potential, integrated education, environmental and economic education, environmental and economic values.

\section{INTRODUCTION}

Modem postindustrial society can be interpreted as the beginning of the transition to a new type of civilizational development, the formation of which is associated not only with the technological revolution but also with the reformation, criticism and revision of a number of previous basic values of anthropogenic culture: the ideals of a consumer society, its attitude to nature and the cult of power as the basis transformative activities. 
Having a powerful potential, ecological and economic ideology, implemented within the framework of cultural and humanistic traditions of education, turns out to be extremely important not only for researchers but also for teachers. The strategic type of ecological and economic consciousness, which is so important and necessary in modern conditions, is especially needed when solving problems that directly or indirectly affect the human environment, the entire sphere of human interaction with nature. It became apparent that the issues of environment and sustainable development cannot be considered separately. World and domestic experience shows that it is impossible to ensure sustainable socio-economic development of society through the destruction of the natural environment and depletion of natural resources, just as it is impossible to maintain the required quality of the environment without a strong economy.

Analysis of the practice of continuing education shows that an effective model of education for sustainable development has not yet developed. The reason is determined by the methodological problem, which consists in the lack of an unambiguous idea of the source of education. Practical activity in all its diversity in the context of a rapid increase in the volume of information cannot provide an adequate selection of the content of education, and science does not fulfill this role since at present there is not only an independent science of sustainable development but also internally consistent scientific concepts of sustainable development.

A transition to a different paradigm of modern science is needed, integrating aspects of economic well-being with the environmental safety of current and future generations of people. The translation of such a productive synthesis, in our opinion, should be the education system, which is the fundamental basis for the formation of the ecological and economic orientation of the individual. It is necessary to introduce a mandatory environmental and economic component into the education system, which, of course, will require the development of innovative goals, objectives, principles, means and technologies of the learning process.

\section{RESEARCH METHODOLOGY}

As a result of the analysis by various social groups of the methods and consequences of the interaction between society and the environment and the subsequently arising complex, often contradictory relations in the political, economic, cultural and social spheres, the principal positions of the agents of ecopolitics are formed and a strategy for resolving environmental problems emerges. Revealing the consistent logic of the transformation of ecological and economic value orientations as management thought evolves will make it possible to interpret the phenomena of the past and the trends of the present, taking into account the deep consumer stereotypes of people's life in the natural environment.

In the scientific literature, the problem of implementing sustainable development is based on the idea of the interdependence of the biosphere and the world economy at the global level since it is their systemic interconnection and the results of systemic interactions that lead to ecological and economic contradictions and create problems that humanity will have to solve in the near future. In his work 'Experience on the Law of Population' (1798), R. Malthus comes to the conclusion that population growth and socio-demographic processes are manageable. 'In the animal and plant world,' Malthus writes further,

nature wisely regulates the seeds of life: enough food - sufficient opportunities for reproduction. The number of plants and animals is limited by the means of subsistence. And the number of people, if you think rationally, cannot but obey this law ... The world, by the will of God, is doomed to starvation and extinction. Only hunger and extinction will balance the amount of mouths and food' [1]. 
Scientists from all over the world are currently dealing with the problems of ecological Marxism, in particular, this area of scientific research is devoted to the article by Wang Zhihe 'Ecological Marxism in China: the emancipation of consciousness and the formation of ecological culture.' The fundamental foundation of the works of Chinese scientists devoted to ecological Marxism are the works of Western authors: B. Agger 'Western Marxism: An Introduction', J. O'Connor 'Natural Causes: Essays on Environmental Marxism', W. Leiss 'The Dominance of Nature' and J. Bellamy 'Environmental Marxism and Ecology against Capitalism' [2].

Solidarity of economists and environmentalists in this case is of particular interest. For example, the Nobel laureate G. Simon, with his idea of bounded rationality, has long resolved the controversial issues concerning the fact that completely rational solutions are often not feasible in practice due to the insolubility of natural decision-making problems and the limited resources available for their adoption. People who make management decisions do not conduct a full analysis of benefits and costs to obtain the optimal option, and they choose the option that meets the criteria of their own usefulness [22].

Describing the evolution of ecological concepts at the beginning of the 20th century, it is necessary to analyze the work of K. Kautsky 'Reproduction and development in nature and society' (1910), in which the author, in our opinion, made a valuable observation that with the increasing domination of human society over nature, the tendency toward upsetting her balance. Anticipating the modern discovery, K. Kautsky describes the dependence of the functioning of any socio-economic system on the universal laws of adaptation.

At the end of the 19th century, V.V. Dokuchaev made an appeal to launch comprehensive studies of integral natural systems. Only the establishment of laws between 'forces', 'bodies' and 'phenomena', between 'dead' and 'living' nature, between plant, animal and mineral kingdoms, on the one hand, and human society, its culture and the spiritual world, on the other, constitutes the essence of cognition of 'nature' [3].

In their scientific works, V.I. Vernadsky noted the ever-increasing role of human activity as a powerful geochemical and geological factor, emphasizing that it was with the appearance of man that a new geological period began, called by the American geologist Ch. Schukhert 'psychozoic' and by the Russian researcher 'anthropogenic'. The history of the appearance of the term can be clearly traced in the book by V.I. Vernadsky 'Essays on Geochemistry', in the paragraph 'Geochemical Activity of Man' [4]. With regard to the qualitatively new state of the biosphere, Vernadsky limited himself to a descriptive interpretation of the semantic definition, while his listener and admirer E. Leroy proposed to call this new stage 'noosphere'.

Lester R. Brown describes the transition to economics as a problem that goes far beyond both economics and ecology [5]. We agree with the author that the path to eco-economics, as well as to improving human population health and social stabilization, lies through the formation of a new system of values. However, we do not support his position that the growth of economic and scientific and technical capabilities in itself does not improve the situation of harmonization of relations between civilization and nature. In the context of our research, we believe that it is economic and scientific and technological progress that is a factor in the harmonization of relations in the system 'man-nature-society' but provided that a person has ecological and economic value orientations that are formed in the process of education.

Thus, the process of establishing a new attitude toward the natural environment was an integral part of a general, global change in scientific, philosophical, ethical and social values of the management sphere. Economists turn to the environmental aspects of the use of natural resources, realizing the impossibility of further economic development without taking into account the consequences inflicted on nature as one or another production decision is 
made. The essence of these changes consisted in radical transitions from mechanicalness to organicity, from materialism to spirituality, from antagonism to unity. The convergence of the parallel evolving ecological and economic paradigms is also evident.

Having a clear understanding of external costs, supporters of neoclassical economic theory emphasize the secondary importance of the problem of environmental externalities, not at all actualizing their importance in the field of management. Increasing the pace of the formation of a market economy, attracting additional workforce, structuring an effective business community is of greater concern to economists.

Optimization of production processes, the emergence of additional workforce, the formation of liquid business structures and the growing pace of the market economy are of greater concern to economists. Determining the value of natural resources based on shadow prices remains a complex issue, the solution of which does not require momentary research on the part of the economy.

Neoclassical economic theory is a highly systematized, well-reasoned premise of a market economy, one of the postulates of which is the limited nature of raw materials, including agricultural: lands, a decrease in their fertility. The views of the neoclassicists provided the basis for the development of a taxation system for the use of natural resources, as well as payments for environmental pollution.

The transition to a market economy only exacerbated the negative trends of previous years - a predatory attitude toward the environment and excessive use of natural resources. Improvement in the XX century of agricultural technology with the widespread use of fertilizers made it possible to increase the yield of fields by four times and the total harvest by six times. The growth in food production and the breakthrough in medicine contributed to an intense increase in the population.

By the beginning of the 20th century, the reserves of extensive growth had been exhausted, but it was still a long way to realizing the criticality of what was happening. The economic thirst for new successes and achievements gave rise to either a 'small victorious war' or a 'revolutionary storm' in the minds of the top political leaders. It is no coincidence that the total military losses of European countries amounted to about 5.5 million people in the 19th century and then in the 20th century, up to 70 million [5]. The growth of needs increases the feeling of permissiveness and omnipotence. American scientist J. Davis, studying the prerequisites of revolutionary crises, mathematically proved that they are always preceded by a period of growth in the quality of life. When the realization comes that the entire strength of human society lies in the amount of natural resources, and they are gradually depleted, the gap gives rise to frustration and hopelessness gives rise to aggression, which pours into the socio-economic system itself.

The radical transformations of the natural environment have led to the need to revise the existing management systems to reassess the socio-economic paradigms and values of the development of society. The processes of defining new vectors of scientific and technological prospects have accelerated. These changes were accompanied by openness and the ability of human society to adapt to changing environmental conditions (the characteristic time of generational change 20-25 years). Fundamental changes in the existing socio-economic paradigms are possible only during the life of three to four generations (50-80 years) [6-7].

The most famous movements and organizations that were engaged in scientific searches for ways out of the existing environmental crisis during this period were the Club of Rome (1968), the idea of creating which belongs to A. Peccei. It was after the first report 'The Limits to Growth' was published that the global ecological catastrophe ceased to be a ghostly 
oppressive dogma but took on a real form and clear time boundaries, constantly narrowing under the influence of scientific and technological progress and human economic activity.

In the last quarter of the 20th century, the world scientific community is increasingly turning to the realization of the need to rethink views on development, the manifestation of moral wisdom in relation to nature and also the consideration of the technological sphere only as an important element in solving environmental problems. The worldview positions adopted for decades exclude the costs of safety and environmental protection, considering them absolutely unprofitable, and, moreover, reducing the competitiveness of the operating industrial giants. However, the planned World Summit on Sustainable Development conference (September 2-11, 2002), which was a continuation of the conferences held in Stockholm (1972) and Rio de Janeiro (1992), discussed problems, priorities and paths for further development of civilization.

The concept of a risk society emerged as a long-awaited response to threats not so much to human health but to the political and economic interests of various social groups. The fundamental basis of the above concept is management assessments of technological risk and social studies of its perception by the population. Quantification of risk has been recognized as a powerful and indisputable argument of industrial corporations for environmental movements. The concept was met with distrust on the part of the population, fueled by the irrational fears of non-specialists.

The concept of environmental modernization prevails in the minds of the highest governing bodies of China, where, since the beginning of the 21 st century, the main goal of state policy has been to solve social problems caused by intensive economic growth through the scientific potential of the Chinese Academy of Sciences, integrated with the translation of the traditional values of the Chinese people.

Considering the inconsistency of environmental and economic motives and needs in the process of interaction of social production with nature, the search for ways to resolve these contradictions is the substantive basis of the process of formation of the ecological and economic orientation of the individual. Each age has its own hierarchy of needs, the leading ones of which determine the direction of the individual. The emergence of ecological and economic needs and motives is the result of an adult's awareness of the ongoing global ecological and economic changes and a clear understanding of the irrevocability to the prevalence of economic values over environmental ones. However, there is still a rather low level of integration of economic and environmental needs.

Eco-economically expedient behavior, the ability to solve the corresponding practical and theoretical problems of the functioning of socio-ecological-economic systems, becomes a potential impetus for harmonious treatment of nature in the future. The development of environmental and economic education is currently determined by interdisciplinary convergence and integration of various fields of knowledge. It is necessary to ensure the possibility of training specialists capable of acting at the intersection of sciences, possessing interdisciplinary knowledge.

The theoretical and methodological basis of the study was made up of the following scientific concepts: the theory of an integrative approach to the design of pedagogical systems (Bezrukova [4, p. 152], Berulava [5, p. 192], Verbitsky [6], etc.); theory of the technogenic influence of society on nature (Bobylev [7], Mella and Gazzola [8], Davankov et al. [9], etc.); the provisions of the integration of ecology and economics in education (Amend and Salamatov [10], Ryabchuk et al. [11], etc.); and an axiological approach to the formation of human potential in the learning process (Kiryakova et al. [12], Amend and Salamatov [10], Slastenin [13, p. 192], etc.). 
In an experimental study of the level of formation of environmental and economic value orientations, methods of sociological research and methods of analysis of empirical information were used (Lapin et al. [14], Rokich [16], etc.).

\section{RESEARCH RESULT}

The deliberate transition from the variability of formulations describing the real forms of the research subject to its inner content is due to a careful search for the category of essence in scientific thinking and cognition. Following the laws and rules of scientific methodology, the modern scientific sphere involves a thorough study of the nature and essence of the studied pedagogical phenomenon, the definition of its properties and fundamental characteristics that fundamentally distinguish it from other categories.

Values, influencing the attitudes of future specialists, turn into the main guideline of professional behavior, lifestyle and subjective reflection of objective activity. Values, influencing the student's attitudes, turn into his human potential, the main reference point for both every day and professional behavior, a way of life and a subjective reflection of objective activity. In addition, interest in the value attitude in the field of pedagogy is primarily caused by its transitional state associated with the reorientation of the value attitudes of society from the consumption of limited resources to the intensive exploitation of human potential, the effective characteristics of which directly depend on the quality of lifelong learning, implemented through innovative pedagogical processes. The search for fundamentally new values that are capable of adequately reflecting the ongoing changes in society translates the axiological approach into the status of the pivotal methodological guideline of modern pedagogical science, which sets the direction and motivation of its future development. That is why values in the process of the educational process are modified into something more, into a personal attitude built into the ideological system of the student's personality. In order to ensure the personal character of the process of forming value orientations, a modern teacher needs an adequate system for diagnosing their presence, as well as an effective toolkit for assigning meaningful values to the student.

In connection with the increase in the expansion of the set of requirements for the formative influence of the education sector on the student's readiness for professional activity with an ecological and economic orientation, the principle of identifying the features of mechanisms, technologies and pedagogical models that predetermine the success of the formative result increases. We attribute the ecological and economic value orientations that a graduate should have to a special category of research. In our opinion, the ecological and economic value orientations of the individual are one of the leading guidelines for modern professional education.

By ecological and economic value orientations, we mean specific formations in the structure of an individual's consciousness, which are subjectively ideal samples and objective guidelines for the ecological and economic activity of an individual and society. The formation of environmental and economic value orientations in the learning process assumes that young people will become aware of their subjective experience, the ability to analyze environmental and economic changes taking place in the modern world, the ability to determine the criteria for the success of a professional decision from an environmental and economic position, the ability to plan and design a personal trajectory with moral convictions, choose techniques and methods of work in an environment with its limited resources, adjust the goals and methods of economic activity and the ability to objectively assess the results of their professional activities in the context of environmental safety and economic feasibility. The ecological and economic value orientations are determined by the general conditions of the 
human environment. They are manifested in the goals, interests of the individual, are determined by his characteristics and life experience, are conditioned and adjusted by the system of upbringing and education, social relations.

By environmental-economic values, we mean specific formations in the structure of the individual's consciousness, which are subjectively ideal samples and objective guidelines for the environmental and economic activities of individuals and societies.

Imagine the environmental-economic (ecological-economic) values in their comparison with the modern personal values of youth (see Table 1). This approach seems to be constructive from the point of view of evaluating the productivity of the system of integrated environmental and economic personal values [15].

Compared with modern personal values, environmental-economic values are more acceptable both from the point of view of a person's moral guidelines and from the point of view of obtaining material wealth for his worthy existence, while resolving the historically established contradiction between environmental and economic values.

The variability of environmental and economic activities is dictated by environmental and economic needs and environmental and economic interests, which are a prerequisite for the formation of an effective modern business ecosystem. Further in Table 2, we have identified the priority environmental and economic areas of activity of future specialists, determined by the close interaction of ecology and economics, mutually conditioning each other (see Table 2).

Table 1: Comparison of environmental-economic values with modern personal values.

Environmental-economic personality Modern personality value value

Enterprise The ability to 'make' money.

Consequence: achieving the goal by any means.

Labor as a means of satisfying needs Labor as a 'punishment' for not being able to raise money in an 'easy way'.

Consequence: laziness, inaction, disorganization, the result of the lack of incentives.

Rational needs

Wastefulness.

Consequence: a strong incentive to achieve success, but not through labor, but at the expense of 'easy money'.

Justice by law Egalitarianism.

Consequence: hostility to upstarts and haves.

Thrift

Responsibility

Human health as a prerequisite for wealth

Scope, breadth, tendency to large-scale affairs. Consequence: negligence, carelessness, fatalism.

The pursuit of quantity to the detriment of quality. Consequence: irresponsibility for the final result.

Work (labor as 'punishment') 'for wear and tear'. Consequence: poor health, reduced life expectancy.

Environmental safety as a condition There are no analogs. for a high quality of life 


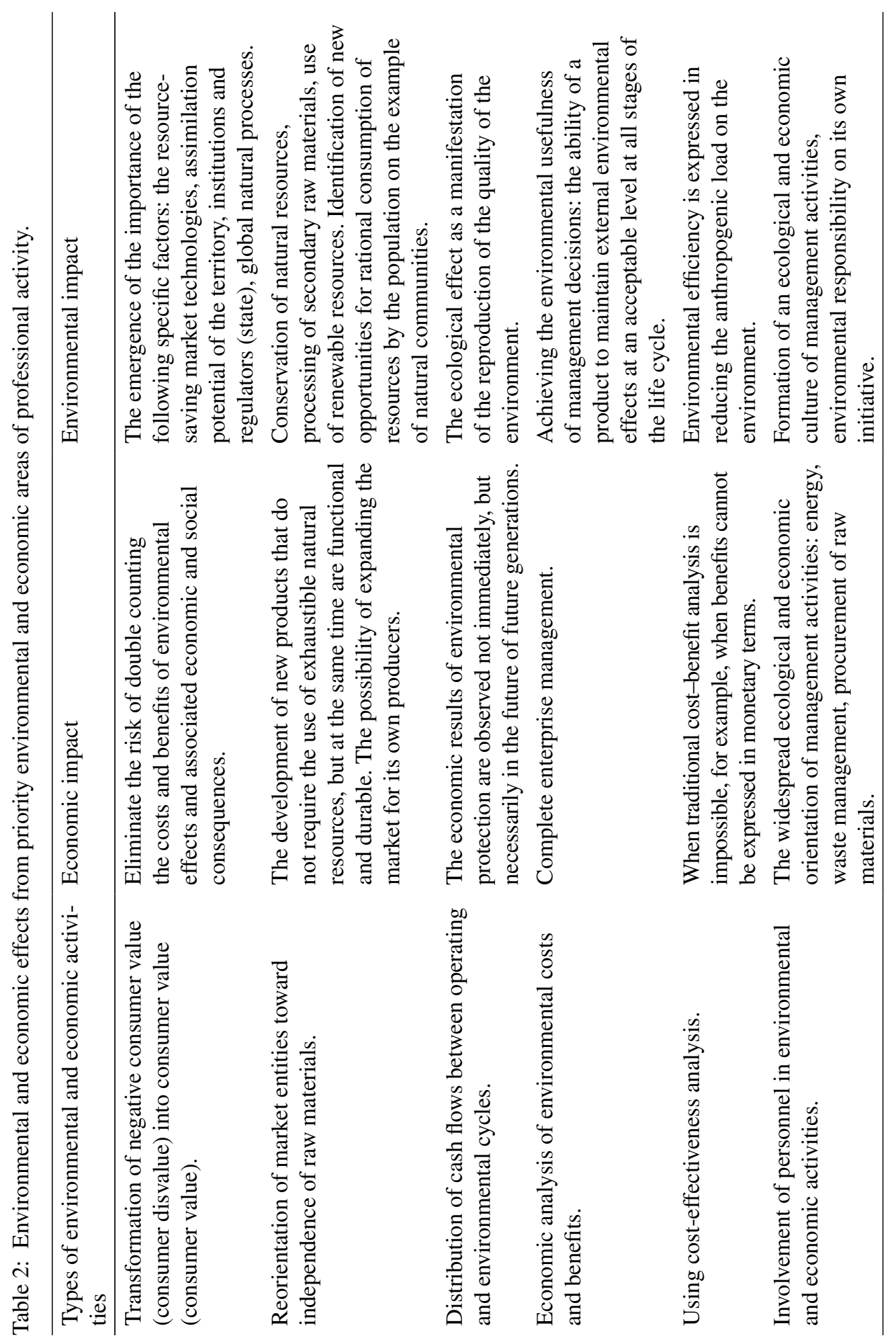




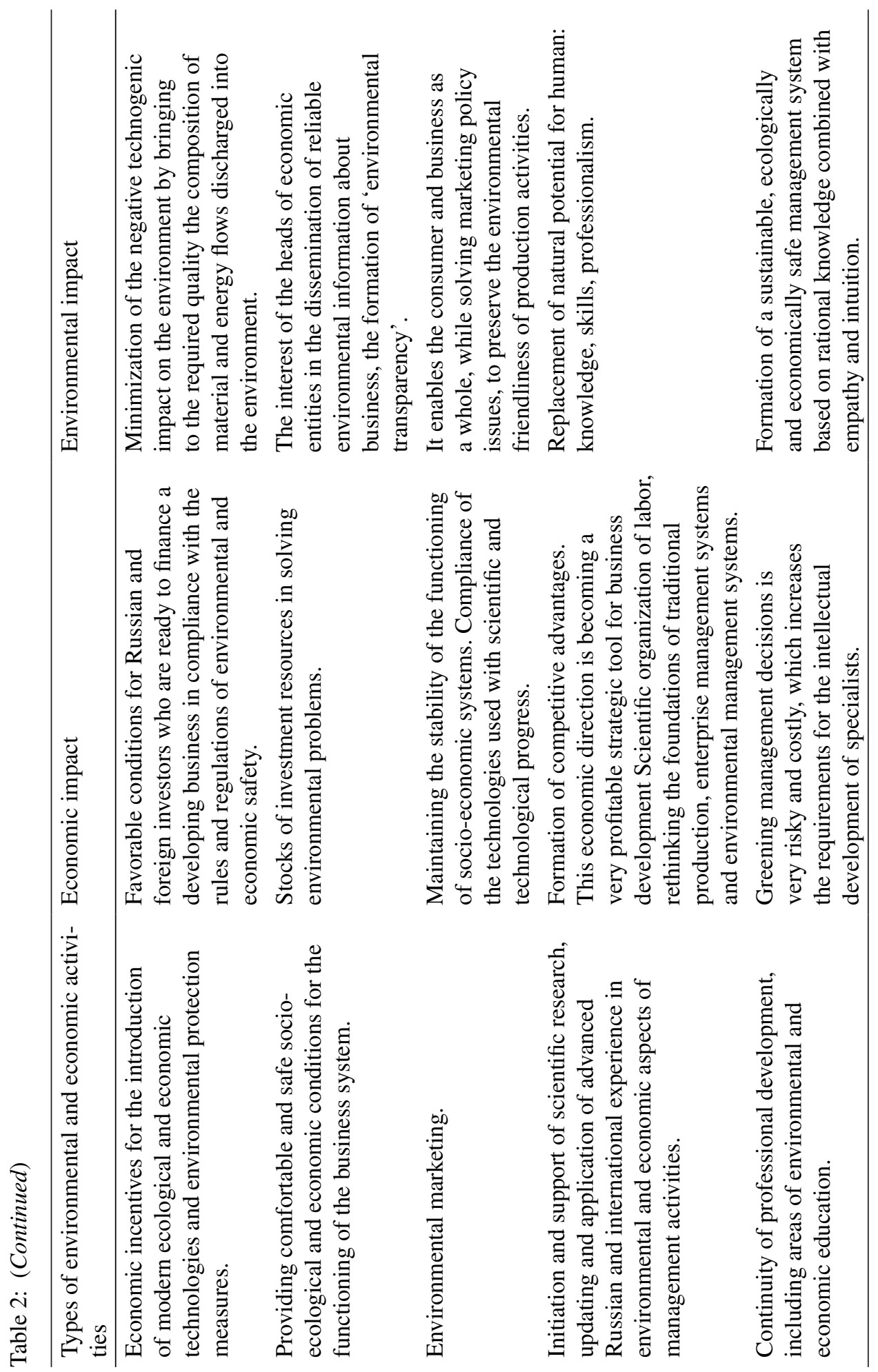


The use of pedagogical innovations within the framework of the formation of a set of socio-psychological, research, activity characteristics, taking into account the orientation of the student's personality, allows us to identify a number of systemic technologies for involving a future specialist in events that are important in the light of his professional prospects.

The problem of the formation of environmental-economic value orientations among students was the subject of a special sociological study.

The sample consisted of 217 students of a pedagogical university in the field of economics and management; computer science and computer engineering; economics and geography; economics and environmental management; mathematics and physics; and mathematics and English. An experimental study was conducted to determine the initial level of formation of environmental and economic value orientations in students. For this, we used the method of Rokich [16], aimed at the diagnosis of terminal (reflecting the goals of existence, priority, significant for the individual) and instrumental (reflecting the type of behavior and personality quality, which are a means of achieving the set life goals) values.

Students were offered a list of 20 values. Students were required to determine for themselves the significance of each value in a given period of their life (the most important thing had to be put in the first place, etc.).

The test results show what place in the value picture of the young man's world is occupied by environmental and economic values along with universal values. In this test, it is important not what of the first places this or that value takes, but what values the student considers insignificant, because it is this that allows one to most accurately penetrate into his value picture of the world.

The data obtained during the study were processed using statistical methods: for each parameter (value), its average $\mathrm{X}$ value was calculated, which made it possible to establish the degree of stability of students' subjective assessments, i.e. determine the value of a particular value in a given period of their life.

An experimental study showed that in terms of overall significance in the hierarchy of values absolutely dominate: family (4.7174); health (6.2391); and education (6.5543).

Further in terms of importance are values such as loyal friends (6.6744); self-realization (7.5435); harmonious development of personality (8.3913); material well-being (9.3478); life as an absolute value (9.8370); respect of comrades (9.9783); personal security (10.4021); biodiversity conservation (14.5000); culture (national and world) (11.6630); religious and spiritual values (7.4239); and maintaining the quality of the natural environment with stable economic well-being (13.5978).

Among the insignificant (those who took the last five places), for the majority of students, terminal values included labor as a means of satisfying needs (15.2174), rational needs (15.5326) and environmental safety (16.6957); among instrumental values - responsibility (16.0217), justice under the law (16.9891) and thrift (17.1304). Thus, in the hierarchy of values of modern youth, environmental-economic values occupy the lowest positions.

The formation of environmental and economic value orientations in the process of integrated environmental and economic education assumes that future specialists will have an awareness of subjective experience, be more able to analyze environmental and economic changes in the modern world, have the ability to determine the criteria for the success of a management decision made from environmental-economic position, have the ability to plan and construct a personal professional trajectory with moral convictions E, choose the techniques and methods of work in the environment with its limited resources, adjust the goals and methods of economic activity and have the ability to objectively assess the results of their professional activities in the context of environmental safety and economic feasibility. 
To solve the problem of formation of environmental and economic orientation of the individual is necessary to apply modern psychological and pedagogical technologies of education, upbringing and development of personality that define and to some extent predict the transformation of consciousness, thinking and activity of the student, not how to change the world through action.

As an example, we can cite the methods of aporetics, the essence of which is reduced to the art of overcoming intractable problems, focusing on the formation of the ability to ask paradoxical questions.

For example, the principle of using the best available technologies in the institutional environment of an enterprise is ambiguous, causing a number of provocative questions about the need to include in the evaluation of production efficiency and the criterion of growth in the company's value, i.e. the ability to focus on future environmental and economic benefits.

Suggested questions:

1) ecological and economic effect of the implementation of projects that contain environmental innovations at the manufacturing enterprise and the use of its products at consumer enterprises;

2) environmental and economic costs from the implementation of projects that contain environmental and economic management innovations at the manufacturing enterprise and additional costs arising in the consumption of products of its manufacture;

3) the economic benefit obtained as a result of the implementation of projects containing innovations of an environmental nature at the manufacturing enterprise and in the application of its products at the consumer enterprise;

4) prevented environmental damage resulting from the implementation of projects containing innovations of an environmental nature at the manufacturing enterprise and at enterprises-consumers of its products;

5) economic benefits from the use of the ecological sign 'environmentally friendly production' at the manufacturing enterprise;

6) the cost of economic resources from the implementation of projects containing environmental innovations and additional costs arising in the consumption of its products;

7) additional environmental costs associated with the implementation of projects containing environmental innovations;

8) transaction costs associated with the implementation of the best available technologies in the enterprise.

The use of pedagogical innovations within the framework of the formation of a set of sociopsychological, research, activity characteristics, taking into account the value orientations of the student's personality, makes it possible to identify a number of systemic technologies for involving a future specialist in events that are important in the light of his professional prospects.

The study presents the following types of professional interests of students:

- economic;

- professional (career);

- intellectual;

- sociocultural;

- ecological;

- environmental and economic. 
Economic interests are a direct manifestation of the content of economic relations and their place in the system of these relations. As a reflection of economic needs directed to the subject area (food, home, etc.), environmental interests are focused on the conditions of life in general, act in some way as the engine of the economic sphere in the dialectical interaction of the objective and subjective components of the interested parties. The transformation of economic interests in the modern economy leads to the formation of relations of social harmony and, ultimately, to social stability in society.

Professional interests include the development of professionally significant personality traits, cognition of the ontological essence of the chosen specialty and an adequate assessment of one's own prospects for the implementation of the knowledge gained with periodic updating. An important condition is the formation of professionally valuable properties and qualities of a person, creative abilities and skills of creative activity, which in the future should become the fundamental foundation of new effective methods of professional activity and personal development as a characteristic of achieving one of the necessary stages of professional growth. Possession of high emotional stability in problematic situations of interpersonal communication, the ability to create trusting and strong relationships are a consequence of such important qualities as the culture of communication, mastery of rhetoric and oratory, skill in presentations and business negotiations.

The sphere of intellectual interests includes the creative and spiritual component of professional socialization, the implementation of the achievements of scientific and technological progress, the expansion of the system of exchange of experience and knowledge in order to strengthen the awareness of the value of the relevant activity that creates an innovative product or service. Scientific substantiation of production and management activities allows us to approach a professional problem more rationally, to identify trends and prospects of ongoing processes and to predict an effective result.

Sociocultural interests are dictated by the sociocultural dynamics of the management sphere: changes in the orientation of the industrial economy toward the knowledge economy with understanding and adherence to universal human values, the formation of a cultural environment for life and a motivated choice by the individual of substantive activity that satisfies not only material but also spiritual and cultural needs.

The environmental interests of the individual are determined by the need for clean air, suitable water for consumption, fertile soil and long-term healthy life. Environmental interests are the most important source of motivation for actions and actions, awareness of the primacy of nature, originality and self-development of a professional's personality.

Environmental and economic interests are manifested in an innovative view of environmental and economic phenomena, sensitivity to new, non-standard, emotional and verbal activity in the process of making managerial decisions and environmental and economic security as an innovative strategy in the management sphere.

The realization of the possibilities of the zone of proximal development in the process of ecological and economic education will be more effective on the basis of the development of promising personal characteristics and the development of the interests and abilities of students within the zone of immediate professional interests.

From a practical point of view, the formation of ecological and economic value orientations is a strategic path aimed at managing one's own professional activity in conditions of uncertainty with the help of reflexive abilities, including:

- the ability to distinguish between economic and environmental-economic problems and to determine the direction of professional decisions in the mainstream of environmental and economic security; 
- the ability to focus on personal needs and motives when solving a managerial task that does not violate the delicate balance in the functioning of ecological and economic systems;

- the ability to make every managerial step the subject of analysis and see its reflection in the development of one's own professional path;

- the ability to 'decompose' the ecological and economic problem, i.e. concretize and structure it, assess environmental, economic and managerial risks and predict the integration mechanisms for their solution;

- the ability to expand the horizons of existing management practice and see new problems arising from previous experience;

- the ability to think tactically, make an optimal decision in conditions of uncertainty and flexibly rebuild as the socio-cultural situation changes;

- the ability to think 'versionally', that is, to think with assumptions, hypotheses and versions;

- the ability to work in a 'system of parallel goals' and to create a 'field of opportunities' for environmental and economic management maneuver;

- the ability to analyze the ecological and economic situation in the dynamics of its development, to foresee near and distant results;

- the ability to integrate various theories of management, ecology and economics to understand their own experience;

- the ability to analyze and accumulate in their experience the best examples of ecological and economically competent management decisions, to be aware of its effectiveness in all possible directions.

\section{CONCLUSIONS}

Value orientations, in our opinion, are a vector directing human potential into the conjuncture of its most effective implementation. The main factor in the formation of value orientations is the reflection of subjective life experience. The prevalence of reflection on action, understanding the preliminary significance of the acquired knowledge, skills and prospects of creative abilities and innovative thinking allow us to bring research in integrated environmental and economic education to a qualitatively new current level of pedagogical problems.

The value-semantic attitude to the world underlies the construction of the life position of the future professional, determining the choice of alternative ways of making professional decisions. Value-semantic constructs determine the trajectory of permissible professional success, limiting the possibilities of crossing the line of morality, morality and ethics. A life strategy arises when not only the final result but also all possible ways to achieve it, the path that a person intends to follow and the objective and subjective resources that he will need for this become the subject of internal reflections.

The process of professional development should combine the optimal ratio of environmental and economic indicators and an increase in environmental and economic responsibility for each implemented option. In turn, professional activity as a form of personality activity, aimed at cognizing and transforming oneself and the surrounding reality, taking into account universal economic and environmental principles, forms the ecological and ecological space of the professional sphere.

Motivation for vital activity should be accompanied by the formation of the ability to self-determination in the ecological and economic relations of the sociocultural path of development, the ability to choose one's own path in an ambiguous and value-contradictory world and improving professional environmental and economic behavior in the management 
sphere. Views and conscious efforts in the process of professional activity in favor of environmental and economic security lead to the transformation of the consumer stereotype of behavior, which must be systemic and can be ensured by the formation of the environmental and economic orientation of the personality of each of the subjects of the management sphere. The ecological and economic orientation of an individual presupposes the presence of corresponding needs and interests, along with motives, goals and beliefs that orient a person toward behavior and activity within the framework of ecological and economic balance. One of the key conditions for the selection of ways to satisfy environmental and economic interests and needs is the desire for professional self-development, self-improvement and environmental and economic activity.

The development of modern methods for the formation of the ecological and economic orientation of the individual for all levels of education and its impact on human behavior and society as a whole is a very relevant and promising direction for further research.

\section{ACKNOWLEDGEMENTS}

The reported study was funded by RFBR, project number 19-29-07209.

\section{REFERENCES}

[1] Malthus, T. R., Experience of the law on population. Part One. Anthology of economic classics, Economv: Moscow, 486 p., 1993.

[2] Hyi, Shin Rui, Vol. 47, № 3, pp. 57-74, 2012 [Electron. resource]. Access mode: http:// adilet.zan.kz/kaz/docs/P1200001124 (access date: 03/05/2018).

[3] Dokuchaev, V. V., Essays: in 9 vols: Publishing house of the USSR Academy of Sciences. - Vol. 9: life and activity of V.V. Dokuchaev. Bibliography of articles / under the editorship of I. V. Tyurin, 327 p., 1961.

[4] Vernadsky, V. I., Biosphere and noosphere, Moscow, 392 p., 1989.

[5] Brown, L.R., Ecoeconomics. How to Create an Economy that Protects the Planet, The Whole World: Moscow, 2003.

[6] Salamatov, A.A., Ecological and economic security of Russia: The future in retrospect. Part One. Society and Power, 1(51), pp. 102-108, 2015.

[7] Salamatov, A.A., Ecological and economic security of Russia: The future in retrospect. Part Two. Society and Power, 2(52), pp. 74-81, 2015.

[8] Bezrukova, V.S., Integration Processes in Pedagogical Theory and Practice, Ekaterinburg, 1994.

[9] Berulava, M.N., Integration of the Content of Education, Perfection: Moscow, 1998.

[10] Verbitsky, A.A., Fundamentals of the concept of the development of continuous environmental education. Pedagogy, 6, pp. 31-36, 1996.

[11] Bobylev, S.N., Sustainable development: A paradigm for the future. World Economy and International Relations, 3(61), pp. 107-113, 2017.

[12] Mella, P. \& Gazzola, P., Sustainability and quality of life: the development model. Enterprise and the Competitive Environment, 2, pp. 542-551, 2015.

[13] Davankov, A.Y., Dvinin, D.Y. \& Postnikov, E.A., Methodological tools for assessing the socio-ecological and economic environment regions within the boundaries of the biosphere stability. Economy of the Region, 4(1 2), pp. 1 029-1039, 2016.

[14] Amend, A.F. \& Salamatov, A.A., Continuous environmental-economic education of students in comprehensive schools. Education and Science, 3(21), pp. 86-96, 2003. 
[15] Ryabchuk, P. et al., Eco-economic security of the region: Expanding the management system for assessing the state of development. International Journal of Supply Chain Management, 7(6), 2018.

[16] Kiryakova, A.V., Olkhovaya, T.A., Melekesov, G.A. \& Presnov, A.A., The axiological approach to the analysis of the problems of modern university education. Mediterranean Journal of Social Sciences, 6(253), pp. 22-28, 2015.

[17] Slastenin, V.A., Introduction to Pedagogical Axiology, Academy: Moscow, 2003.

[18] Lapin, N.I., Ossadtchaya, G.I. \& Yadov, V.A., Integrating university sociological education and scholarly research. Sotsiologicheskie Issledovaniya, 2, pp. 106-111, 2002.

[19] Rokich, M., Methodology "Value Orientations", Big Encyclopedia of Psychological Tests: Moscow, pp. 26-28, 2009.

[20] Salamatov, A.A., Gnatyshina, E.A. \& Gordeeva, D.S., The concept of sustainable environmental and economic development in the transition to the digital economy. Proceedings of the International Scientific and Practical Conference on Digital Economy (ISCDE 2019), pp. 857-862, 2019.

[21] Salamatov, A., Gordeeva, D., Agapov, A., Integrated Environmental and Economic Education as a Factor of Sustainable Development of Modern Society. Fifth International Conference on Environmental and Economic Impact on Sustainable Development "Environmental Impact V”. WIT Transactions on Ecology and the Environment, Vol. 245, pp. 157-163, 2020.

[22] Simon H. Administrative Behavior: A Study of Decision-making Processes in Administrative Organizations. N.Y.: The Free Press, 1997. (First published in 1945.) 